\title{
Barriers and incentives for Italian paediatricians to become smoking cessation promoters: a GARD-Italy Demonstration Project
}

\author{
Giovanna Cilluffo ${ }^{1 \#}$, Giuliana Ferrante ${ }^{2 \#}$, Renato Cutrera ${ }^{3}$, Giorgio Piacentini ${ }^{4}$, Elisabetta Bignamini ${ }^{5}$, \\ Massimo Landi ${ }^{6}$, Paola Martucci ${ }^{7}$, Luigi Morcaldi ${ }^{8}$, Fabio Midulla ${ }^{9}$, Giovanni Viegi ${ }^{110}$, Stefania La Grutta $^{1}$ \\ ${ }^{1}$ Institute for Biomedical Research and Innovation (IRIB), National Research Council (CNR), Palermo, Italy; ${ }^{2}$ Department of Health Promotion, \\ Mother and Child Care, Internal Medicine and Medical Specialties, University of Palermo, Palermo, Italy; ${ }^{3}$ University Department of Pediatrics \\ (DPUO), Bambino Gesù Children's Hospital, Rome, Italy; ${ }^{4}$ Department of Surgical Sciences, Dentistry, Gynaecology and Paediatrics, University \\ of Verona, Verona, Italy; ${ }^{5}$ Pediatric Pulmonology, Cystic Fibrosis Centre, AOU Città della Salute e della Scienza, Torino, Italy; ${ }^{6}$ National Paediatric \\ Health Care System (NPHCS), Torino, Italy; 'Unit of Interventional Pneumology, Azienda Ospedaliera di Rilievo Nazionale "Antonio Cardarelli”, \\ Naples, Italy; ${ }^{8}$ National Paediatric Health Care System (NPHCS), Salerno, Italy; ${ }^{9}$ Department of Pediatrics, "Sapienza” University of Rome, Rome, \\ Italy; ${ }^{10}$ Institute of Clinical Physiology, Pulmonary Environmental Epidemiology Unit, National Research Council (CNR), Pisa, Italy \\ Contributions: (I) Conception and design: R Cutrera, S La Grutta; (II) Administrative support: R Cutrera; (III) Provision of study materials or patients: \\ P Martucci, L Morcaldi; (IV) Collection and assembly of data: R Cutrera, G Piacentini, E Bignamini, M Landi, F Midulla; (V) Data analysis and \\ interpretation: G Cilluffo; (VI) Manuscript writing: All authors; (VII) Final approval of manuscript: All authors. \\ \#These authors contributed equally to this work. \\ Correspondence to: Giuliana Ferrante, MD, PhD. Department of Health Promotion, Mother and Child Care, Internal Medicine and Medical \\ Specialties, University of Palermo, Piazza delle Cliniche, 2, 90127 Palermo, Italy. Emai: giuliana.ferrante@unipa.it.
}

Background: Paediatricians rarely devote any time to screening and treatment for parental tobacco use. The present project is part of a Global Alliance against Chronic Respiratory Diseases (GARD)-Italy Demonstration Project, aimed to increase the skills of primary care physicians and paediatricians as "promoter of smoking cessation". The aims of this study were: (I) to identify latent classes of barriers and incentives for smoking cessation counseling among paediatricians using latent class analysis (LCA); (II) to investigate risk factors for inclusion into the identified classes.

Methods: In 2018, 1,500 Italian paediatricians were invited to complete an online survey on passive smoke exposure in children. LCA was used to discover underlying response patterns, and to identify respondent groups with similar attitudes toward passive smoke exposure in children. Multinomial logistic regression helped investigate which explanatory variables influenced inclusion into a class. A P value $<0.05$ was considered significant.

Results: The overall response rate was $71 \%(\mathrm{n}=1,071 / 1,500)$. Three classes were identified: Class 1 "passive" ( $\mathrm{n}=226,21.10 \%)$; Class 2 "unmotivated" ( $\mathrm{n}=124,11.58 \%)$; and Class 3 "proactive" ( $\mathrm{n}=721,67.32 \%)$. Assuming Class 3 as reference, ever having been a smoker was borderline associated $(\mathrm{P}=0.052)$ with increased probability of inclusion into Class 1 (OR $=1.43,95 \%$ CI, 1.00-2.06). Having 6-15 or $\geq 15$ years of work experience versus having less than five years was associated with decreased probability of being in the "passive" class $(\mathrm{OR}=0.46,95 \% \mathrm{CI}, 0.22-0.96$ and $\mathrm{OR}=0.49,95 \% \mathrm{CI}, 0.27-0.87$, respectively), as was discussing parents' addiction to alcohol/drugs ( $\mathrm{OR}=0.50,95 \% \mathrm{CI}, 0.33-0.76)$.

Conclusions: We identified three profiles among Italian paediatricians related to barriers and incentives for smoking cessation promotion. Tailored educational interventions for paediatricians are required to promote smoking cessation programs.

Keywords: Latent class analysis (LCA); paediatricians; smoking cessation; barriers; incentives 
Submitted Jul 04, 2020. Accepted for publication Oct 27, 2020.

doi: 10.21037/jtd-gard-20-003

View this article at: http://dx.doi.org/10.21037/jtd-gard-20-003

\section{Introduction}

Exposure to secondhand smoke (SHS) has been linked to many diseases, particularly in children (1-3). The WHO Framework Convention on Tobacco Control suggests that, amongst effective tobacco control measures, brief advice should be integrated into primary care services (4): it usually takes only a few minutes. Some studies, however, demonstrated that paediatricians rarely devote any time to screening and treatment for parental tobacco use (5-7) due to lack of responsibility (8) and absence of $a d$ boc training (9-11).

Previous studies evaluated paediatrician's adherence to the guidelines on smoking cessation counseling $(5,12,13)$, highlighting a variety of factors which may affect their attitude to screening and treatment for parental tobacco use in the clinical setting. However, no study evaluating profiles of paediatricians with regard to barriers and/or incentives for smoking cessation counseling has been performed so far.

The Action Plan of the Global Alliance against Chronic Respiratory Diseases (GARD) 2008-2013 is an instrument of the Action Plan for the Global Strategy for Prevention and Control of Noncommunicable Diseases adopted by the World Health Assembly in May 2008. The GARD strategy promotes preventive tasks at a local and global level for preventing chronic respiratory diseases. The present GARD-Italy Demonstration Project "Advice for Smoking Cessation in Pediatric Care: the Minimal Advice Project" (MAPed) aims to promote smoking cessation in adolescents, parents/caregivers and pregnant women.

The MAPed consists of three main parts: (I) screening of barriers and incentives for smoking cessation counseling among paediatricians; (II) national education campaign; (III) assessing barriers and incentives for smoking cessation counseling after the MAPed project (Figure 1). The current study reports data from the first part of the project. The use of a data-driven approach, such as latent class analysis (LCA), would be helpful at this purpose by assigning respondents into classes based on their responses to questionnaire items, without any interference from the researcher (14-16).

The aims of this study were: (I) to identify latent classes of barriers and incentives for smoking cessation counseling among paediatricians; (II) to investigate risk factors for inclusion into the identified classes.

We present the following article in accordance with the STROBE reporting checklist (available at http://dx.doi. org/10.21037/jtd-gard-20-003).

\section{Methods}

\section{Advice for Smoking Cessation in Pediatric Care: the Minimal Advice Project (MAPed)}

After the approval by the GARD Executive Committee, the MAPed started with an ad-hoc online survey aimed at assessing knowledge and skills of paediatricians in delivering adequate advice to smokers, as well as barriers and incentives to become smoking cessation promoters.

A specific website accessible with a personal login was prepared for the study. Interested paediatricians were asked to login to the Italian Paediatric Respiratory Society - IPRS (SIMRI in Italian) - website: after registration, the survey was completed online.

Participation was voluntary and anonymous-no names or information identifying individuals were recorded. Access to the website was denied, once the completed survey was sent.

\section{Self-administered PSEC questionnaire}

The self-administered online questionnaire Passive Smoke Exposure in Children (PSEC-Q) was constructed based on a prior study on this issue (13). The PSEC-Q final version was the result of expert agreement by all the Authors who are specialists in the fields of paediatrics, family medicine, psychology, and smoking cessation promotion.

PSEC-Q was built with the aims of: collecting paediatricians' personal information (Section A); identifying the barriers that prevent discussing PSEC with parents during the medical visit (Section B); detecting incentives that encourage the paediatrician to discuss PSEC with parents during the medical visit (Section C); evaluating the paediatricians' attitude to discuss issues of concern with parents during the medical visit (Section D) (see Appendix 1 for more detail). 


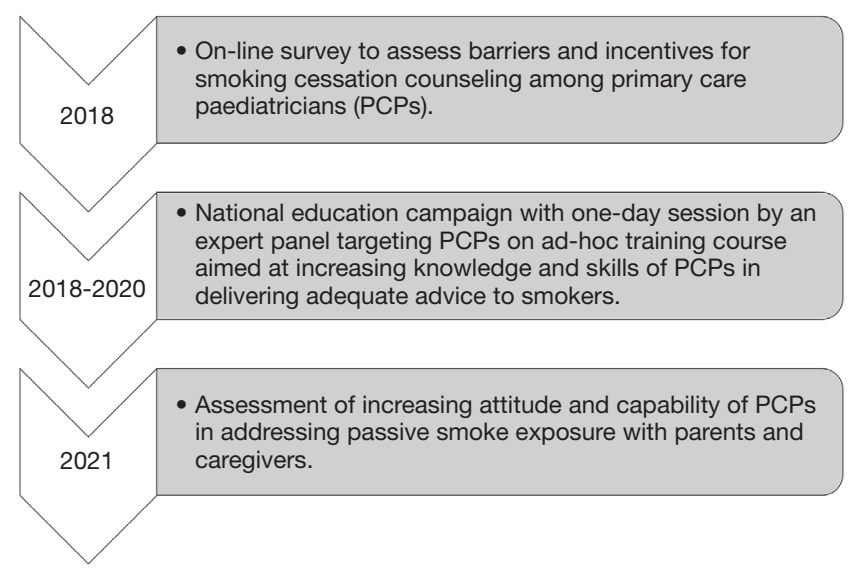

Figure 1 The Minimal Advice Project (MAPed) flow-chart.

\section{Statistical analysis}

Data were presented as $\mathrm{n}(\%)$. Differences of categorical variables were analyzed using the Chi-squared test. LCA was used to discover underlying response patterns, as well as for identifying respondent groups with similar attitudes toward children's SHS exposure. LCA was computed using the $\mathrm{R}$ poLCA package, which estimates the latent class model by maximizing, with respect to $p_{r}$ and $\pi_{j r k}$, the following log-likelihood function:

$$
\ln L=\sum_{i=1}^{N} \ln \sum_{r=1}^{R} p_{\mathrm{r}} \prod_{j=1}^{J} \prod_{k=1}^{k_{j}} \pi_{j r k} Y_{i j k}
$$

where $\mathrm{J}$ indicates polytomous categorical variables (manifest variables), each containing $\mathrm{K}_{\mathrm{j}}$ possible outcomes, for individuals $\mathrm{i}=1 \ldots \mathrm{N} ; Y_{i j k}$ denotes observed values of $\mathrm{J}$ manifest variables such that $Y_{i j k}=1$ if the respondent $i$ gives the $\mathrm{k}$-th response to the $\mathrm{j}$-th variable, and $Y_{i j k}=0$ otherwise; $\pi_{j r k}$ denotes class-conditional probability that an observation in class $\mathrm{r}=1 \ldots \mathrm{R}$ produces the $\mathrm{k}$-th outcome on the $\mathrm{j}$-th variable and $p_{r}$ indicates $\mathrm{R}$ mixing proportions. poLCA takes advantage of the iterative nature of the expectationmaximization algorithm to make it possible to estimate the latent class model even when some of the observations on the manifest variables are missing. All associations among included variables are assumed as entirely due to distinct subpopulations called "latent classes". Within these classes, all variables are assumed to be independent (17). Variable selection for LCA was performed in order to find the set of variables with relevant clustering information and to discard those that were redundant and/or not informative. For performing variable selection, we started from a full model and we deleted variables which were not statistically different between the classes in the various LCA solutions.

Then, we considered the two above mentioned questionnaire sections, i.e., (I) barriers concerning PSEC (8 items from Section B), and (II) incentives concerning PSEC (5 items from Section C). The answers which were very applicable and quite applicable from Section B and those which were not very likely and unlikely from Section $\mathrm{C}$ were aggregated in so far as they were less frequently indicated by respondents. Answers to these items (i.e., manifest variables) were used to categorize respondents into groups with similar response profiles (i.e., latent classes). Akaike Information Criterion (AIC), Bayesian Information Criterion (BIC) and Consistent AIC (CAIC) $(14,18)$ were computed in order to select the best number of classes. LCA class comparisons were analyzed using the Chi-squared test. A multinomial logistic regression model was used to investigate which explanatory variables influenced inclusion into a latent class.

A full model including all questions of Sections A and D was estimated. Using a BIC-based stepwise procedure, a reduced model was obtained. Odds ratios (ORs) and their relative $95 \%$ confidence intervals (CIs) were computed to describe associations' strength. Class 3 was used as the reference group.

Analyses were performed with R 3.5.2 software. A P value $\leq 0.05$ was considered significant.

\section{Results}

\section{Characteristics of the study population}

A total of 1,071 paediatricians out of 1,500 participated in the survey (response rate $=71 \%$ ).

Table 1 reports answers to the questions of Sections A and B. In Section A (personal information), 32.38\% of the respondents were males, and $79.05 \%$ had more than 15 years of work experience; approximately $34.28 \%$ had ever smoked, and 64\% were exposed to passive smoke during childhood. In Section B (barriers), the most frequently reported barriers were lack of time (very applicable: $7.52 \%$ ) and privacy (very applicable: $5.63 \%$ ).

Table 2 reports answers to the questions of Section $\mathrm{C}$ (incentives). Evidence of children with asthma-related disorders (very likely: $80.59 \%$ ), smelling of tobacco (very likely: $78.41 \%$ ), and smoking parents (very likely: $71.79 \%$ ) were the most frequent drivers of PSEC discussion.

Finally, regarding Section D (discussed topics) 
Table 1 Characteristics of the respondents and barriers reported

\begin{tabular}{|c|c|}
\hline Characteristics & Number (\%), $\mathrm{n}=1,071$ \\
\hline \multicolumn{2}{|l|}{ Section A (demographics) } \\
\hline Sex: male & $338(32.38)$ \\
\hline \multicolumn{2}{|l|}{ Work experience, years } \\
\hline$\leq 5$ & $89(8.44)$ \\
\hline $6-15$ & $132(12.51)$ \\
\hline$\geq 15$ & $834(79.05)$ \\
\hline \multicolumn{2}{|l|}{ Do you smoke? } \\
\hline Never & $669(65.72)$ \\
\hline Ever smoker & $349(34.28)$ \\
\hline $\begin{array}{l}\text { Have you ever been exposed to } \\
\text { passive smoke during childhood? }\end{array}$ & $661(64.61)$ \\
\hline \multicolumn{2}{|l|}{ Section B (barriers) } \\
\hline \multicolumn{2}{|c|}{ Speaking of this topic I invade the privacy of parents } \\
\hline Very applicable & $49(5.63)$ \\
\hline Quite applicable & $189(21.72)$ \\
\hline Neutral & $258(29.66)$ \\
\hline Not very applicable & $180(20.69)$ \\
\hline Inapplicable & $194(22.30)$ \\
\hline \multicolumn{2}{|c|}{$\begin{array}{l}\text { I expect that discussing this topic may compromise the } \\
\text { doctor/patient relationship }\end{array}$} \\
\hline Very applicable & $27(3.11)$ \\
\hline Quite applicable & $132(15.22)$ \\
\hline Neutral & $231(26.64)$ \\
\hline Not very applicable & $263(30.33)$ \\
\hline Inapplicable & $214(24.68)$ \\
\hline \multicolumn{2}{|c|}{ I have no time to discuss the topic during the visit } \\
\hline Very applicable & $64(7.52)$ \\
\hline Quite applicable & $179(21.03)$ \\
\hline Neutral & $171(20.09)$ \\
\hline Not very applicable & $215(25.26)$ \\
\hline Inapplicable & $222(26.09)$ \\
\hline \multicolumn{2}{|c|}{$\begin{array}{l}\text { I do not consider the subject so important to be faced during a } \\
\text { medical examination }\end{array}$} \\
\hline Very applicable & $27(3.25)$ \\
\hline Quite applicable & $67(8.06)$ \\
\hline Neutral & $88(10.59)$ \\
\hline
\end{tabular}

Table 1 (continued)
Table 1 (continued)

\begin{tabular}{cc}
\hline Characteristics & Number $(\%), \mathrm{n}=1,071$ \\
\hline Not very applicable & $243(29.24)$ \\
Inapplicable & $406(48.86)$
\end{tabular}

There is no need to tackle this topic during the medical examination, as nothing will change for the child

$\begin{array}{lc}\text { Very applicable } & 26(3.16) \\ \text { Quite applicable } & 80(9.72) \\ \text { Neutral } & 104(12.64) \\ \text { Not very applicable } & 230(27.95) \\ \text { Inapplicable } & 383(46.54)\end{array}$

I do not consider it my responsibility to talk about this topic during the medical examination

$\begin{array}{lc}\text { Very applicable } & 33(3.99) \\ \text { Quite applicable } & 54(6.53) \\ \text { Neutral } & 63(7.62) \\ \text { Not very applicable } & 216(26.12) \\ \text { Inapplicable } & 461(55.74)\end{array}$

I have no knowledge on the subject that I can deal with during the medical examination

$\begin{array}{lc}\text { Very applicable } & 17(2.06) \\ \text { Quite applicable } & 61(7.38) \\ \text { Neutral } & 104(12.59) \\ \text { Not very applicable } & 246(29.78) \\ \text { Inapplicable } & 398(48.18)\end{array}$

I have limited communication skills to address this topic during the medical examination

$\begin{array}{lc}\text { Very applicable } & 31(3.73) \\ \text { Quite applicable } & 79(9.51) \\ \text { Neutral } & 99(11.91) \\ \text { Not very applicable } & 233(28.04) \\ \text { Inapplicable } & 389(46.81)\end{array}$

(Table 3), $59.33 \%$ of respondents always talked to families about smoke exposure at home, $46.39 \%$ always discussed consequences of passive smoke, and $46.39 \%$ offered information about passive smoke effects on children's health. Among those assessing PSEC, 97.51\% advised parents to stop smoking, $91.97 \%$ were convinced that paediatricians should talk about PSEC, and $79.20 \%$ were 
Table 2 Incentives reported by respondents

\begin{tabular}{|c|c|}
\hline Section C (incentives) & Number (\%) \\
\hline \multicolumn{2}{|c|}{ A child who complains of asthma-related disorders } \\
\hline Very likely & $768(80.59)$ \\
\hline Likely & $161(16.89)$ \\
\hline Not very likely & $16(1.68)$ \\
\hline Unlikely & $8(0.84)$ \\
\hline \multicolumn{2}{|c|}{ A family with a history of sudden infant death syndrome } \\
\hline Very likely & $355(41.47)$ \\
\hline Likely & $196(22.90)$ \\
\hline Not very likely & $190(22.20)$ \\
\hline Unlikely & $115(13.43)$ \\
\hline \multicolumn{2}{|c|}{ A child with otitis media with effusion } \\
\hline Very likely & $242(28.17)$ \\
\hline Likely & $301(35.04)$ \\
\hline Not very likely & $235(27.36)$ \\
\hline Unlikely & $81(9.43)$ \\
\hline \multicolumn{2}{|c|}{ The smell of tobacco around the child and/or parent } \\
\hline Very likely & $770(78.41)$ \\
\hline Likely & $154(15.68)$ \\
\hline Not very likely & $37(3.77)$ \\
\hline Unlikely & $21(2.14)$ \\
\hline \multicolumn{2}{|c|}{$\begin{array}{l}\text { The visible presence of cigarettes or smoking accessories with } \\
\text { the parent }\end{array}$} \\
\hline Very likely & 659 (71.79) \\
\hline Likely & 168 (18.30) \\
\hline Not very likely & $59(6.43)$ \\
\hline Unlikely & 32 (3.49) \\
\hline
\end{tabular}

interested in a training course on PSEC.

\section{LCA}

Figure S1 reports AIC, BIC and CAIC obtained by 5 models; the 3-class solution (Model 2) was chosen as the best, in view of the lowest BIC. The percentage of missing for each variable of interest is reported in Figure S2.

Figure 2 illustrates the three identified classes using the LCA-Model 2.

Class $1(n=226,21.10 \%)$ : passive, which was mainly
Table 3 Discussed topics by respondents

\begin{tabular}{lc}
\hline Section D (discussed topics) & Number (\%) \\
\hline Does any member of your family smoke? & $588(59.33)$ \\
Always & $284(28.66)$ \\
Often & $97(9.79)$ \\
Occasionally & $22(2.22)$ \\
Never & $633(63.55)$ \\
Does anyone smoke in the presence of your child? \\
Always & $259(26.00)$ \\
Often & $80(8.03)$ \\
Occasionally & $24(2.41)$ \\
Never & \\
Does anyone smoke inside your car? & $493(50.88)$ \\
Always & $251(25.90)$ \\
Often & $153(15.79)$ \\
Occasionally & $72(7.43)$ \\
Never &
\end{tabular}

Did you make efforts to prevent your child's passive smoking?

$\begin{array}{lc}\text { Always } & 388(40.71) \\ \text { Often } & 334(35.05) \\ \text { Occasionally } & 170(17.84) \\ \text { Never } & 61(6.40)\end{array}$

Is the parent aware of the consequences of passive smoking on the health of the child?

$\begin{array}{lc}\text { Always } & 462(46.39) \\ \text { Often } & 330(33.13) \\ \text { Occasionally } & 173(17.37) \\ \text { Never } & 31(3.11)\end{array}$

Do you provide information on the effects on children's health caused by exposure to passive smoking?

$\begin{array}{lc}\text { Always } & 465(44.84) \\ \text { Often } & 437(42.14) \\ \text { Occasionally } & 130(12.54) \\ \text { Never } & 5(0.48)\end{array}$

Could you indicate your difficulty in dealing with the argument of overweight and/or obesity in children during the medical examination?

Very difficult

36 (3.75) 
Table 3 (continued)

\begin{tabular}{lc}
\hline Section D (discussed topics) & Number $(\%)$ \\
\hline Difficult & $170(17.73)$ \\
Neutral & $71(7.40)$ \\
Easy & $345(35.97)$ \\
Very easy & $337(35.14)$
\end{tabular}

Could you indicate what is your degree of difficulty in dealing with the topic of parental negligence towards children during the medical examination?

$\begin{array}{lc}\text { Very difficult } & 111(11.82) \\ \text { Difficult } & 434(46.22) \\ \text { Neutral } & 119(12.67) \\ \text { Easy } & 197(20.98) \\ \text { Very easy } & 78(8.31)\end{array}$

Could you indicate what your difficulty level is in addressing the subject of child abuse during the medical examination?

$\begin{array}{lc}\text { Very difficult } & 323(34.69) \\ \text { Difficult } & 400(42.96) \\ \text { Neutral } & 83(8.92) \\ \text { Easy } & 77(8.27) \\ \text { Very easy } & 48(5.16)\end{array}$

Could you indicate what is your difficulty level in addressing the topic of exposure of the child to passive smoking during the medical examination?

$\begin{array}{lc}\text { Very difficult } & 8(0.84) \\ \text { Difficult } & 58(6.07) \\ \text { Neutral } & 86(9.01) \\ \text { Easy } & 428(44.82) \\ \text { Very easy } & 375(39.27)\end{array}$

Could you indicate what your difficulty level is in addressing the subject of parent's dependencies during the medical examination?

Very difficult 95 (10.29)

Difficult

$271(29.36)$

Neutral

177 (19.18)

Easy

256 (27.74)

Very easy

$124(13.43)$

Do you advise smokers in the family to stop $900(97.51)$ smoking in the presence of the child?

Table 3 (continued)
Table 3 (continued)

\begin{tabular}{lc}
\hline Section D (discussed topics) & Number (\%) \\
\hline $\begin{array}{l}\text { From your point of view, who is in charge of discussing exposure } \\
\text { to passive smoking in children? }\end{array}$ & $985(91.97)$ \\
Paediatrician & $158(14.75)$ \\
Pulmonologist & $236(22.04)$ \\
General medical practitioner & $451(44.48)$ \\
Have you ever received post-graduate & \\
training on exposure to passive smoking in \\
children? \\
$\begin{array}{l}\text { Would you be interested in receiving training } \\
\text { on exposure to passive smoking in children? }\end{array}$
\end{tabular}

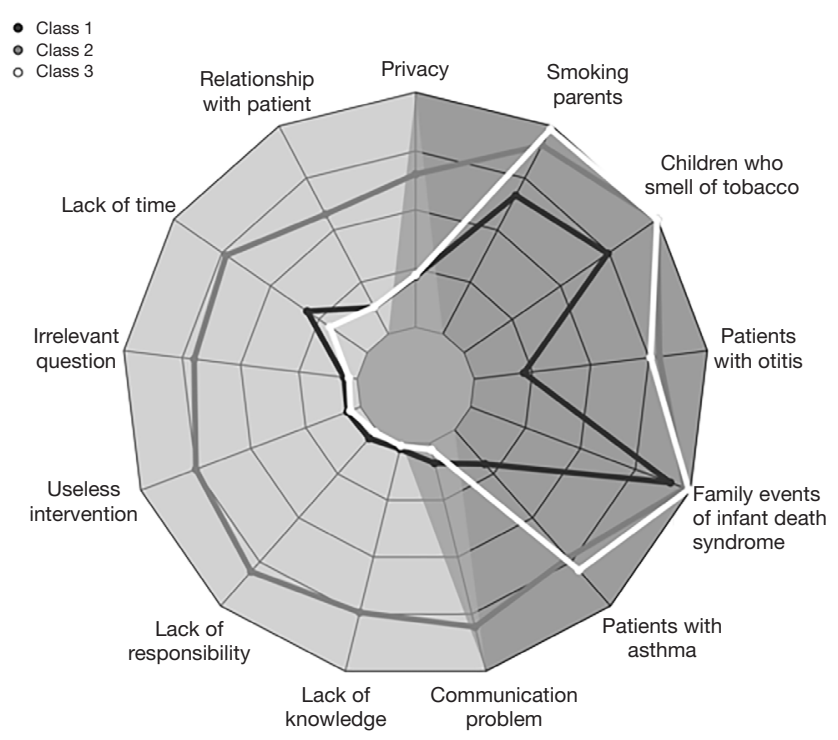

Figure 2 Radar plot comparing the three latent classes. Light grey background highlights the barriers, dark grey background highlights the incentives. Each segment from the center of the radar to the top is $25 \%$.

composed of paediatricians who reported very low frequencies of privacy $(21.56 \%)$, relationship with patients $(12.82 \%)$, and lack of time (31.04\%) as barriers. Evidence of children with asthma (90.90\%) and tobacco smell (74.34\%) were incentives.

Class 2 ( $\mathrm{n}=124,11.58 \%)$ : unmotivated, which was mainly composed of paediatricians who reported the highest frequencies of privacy $(65.21 \%)$, lack of time $(72.95 \%)$, 
irrelevant question (69.92\%), useless intervention (74.99\%), lack of responsibility (80.56\%), lack of knowledge (74.27\%) and communication problems $(80.61 \%)$ as barriers. In addition, they had reasonably elevated frequencies of evidence of asthma in children $(97.50 \%)$, children who smelled of tobacco (100\%), and smoking by the parents (90.74\%) as incentives.

Class 3 ( $n=721,67.32 \%)$ : proactive, which was mainly composed of paediatricians who reported the lowest frequencies of barriers such as irrelevant question (3.6\%), useless intervention (4.6\%), lack of responsibility (1.1\%) and communication problems $(2.9 \%)$ as well as the highest frequencies of evidence of asthma in children (99.22\%), otitis media in children $(75.70 \%)$, children smelling of tobacco $(99.82 \%)$, parents who smoked $(98.44 \%)$, and a family event of children's sudden infant death syndrome (79.71\%), as incentives.

\section{LCA class comparisons}

Table 4 reports the main characteristics of paediatricians and issues discussed with parents during the medical visit stratified by LCA class. Paediatricians in Class 3 more frequently addressed PSEC if there were smokers in the family (Class 1: 49.54\%, Class 2: 47.66\%, Class 3: 68.53\%, $\mathrm{P}<0.001$ ), if someone smoked in the car (Class 1: 69.96\%, Class 2: $78.18 \%$, Class 3: $78.93 \%, \mathrm{P}=0.022)$. Paediatricians in Class 2 more frequently addressed if any actions were taken to prevent children from PSEC (Class 1: 65.91\%, Class 2: $82.41 \%$, Class 3: $78.08 \%, \mathrm{P}<0.001)$. Paediatricians in Class 3 more frequently informed parents about PSEC effects on children's health (Class 1: $82.88 \%$, Class 2: $82.79 \%$, Class 3: $89.03 \%, \mathrm{P}<0.001)$. Paediatricians in
Class 2 more frequently addressed psychological or sexual abuse (Class 1: 11.00\%, Class 2: 20.72\%, Class 3: 12.93\%, $\mathrm{P}=0.044)$. Table $\mathrm{S} 1$ reports the answers to the discussed topics of the respondents stratified by LCA class in more detail.

\section{Multinomial logistic regression}

The estimated ORs and 95\% CIs for inclusion into a class are reported in Figure 3. Some significant associations were found when comparing Class $1 v v$. Class 3. Being an ever smoker was borderline $(\mathrm{P}=0.052)$ associated with an increased probability of being in the passive class (OR $=1.43,95 \%$ CI, $1.00-2.06$ ). Having $6-15$ years or $15+$ years of work experience versus less than five years was associated with a decreased probability of being in the passive class (OR $=0.46,95 \%$ CI, $0.22-0.96$ and $\mathrm{OR}=0.49,95 \%$ CI, $0.27-$ 0.87 , respectively). Further, discussing parents' addiction to alcohol/drugs was associated with a decreased probability of being in the passive class ( $\mathrm{OR}=0.50,95 \% \mathrm{CI}, 0.33-0.76$ ). No significant associations were found in comparing Class 2 and Class 3.

\section{Discussion}

Based on their answers to the PSEC-Q questionnaire, we identified three profiles among Italian paediatricians related to barriers and incentives for smoking cessation promotion. Specifically, "passive" paediatricians (not addressing PSEC despite few barriers and some incentives), "unmotivated" paediatricians (not addressing PSEC due to many barriers in spite of many incentives), "proactive" paediatricians (addressing PSEC due to few barriers and many incentives).

Table 4 Main characteristics and discussed topics of the respondents by LCA classes

\begin{tabular}{|c|c|c|c|c|}
\hline Characteristics & $\begin{array}{l}\text { Class 1: passive } \\
(n=226), n(\%)\end{array}$ & $\begin{array}{l}\text { Class 2: unmotivated } \\
\qquad(\mathrm{n}=124), \mathrm{n}(\%)\end{array}$ & $\begin{array}{l}\text { Class 3: proactive } \\
(\mathrm{n}=721), \mathrm{n}(\%)\end{array}$ & $P$ value \\
\hline Sex: male & 79 (35.27) & 41 (33.61) & $218(31.23)$ & 0.507 \\
\hline Work experience, years & & & & 0.019 \\
\hline$\leq 5$ & 30 (13.33) & $8(6.56)$ & $51(7.20)$ & \\
\hline $6-15$ & $26(11.56)$ & $10(8.20)$ & $96(13.56)$ & \\
\hline$\geq 15$ & $169(75.11)$ & $104(85.25)$ & $561(79.24)$ & \\
\hline
\end{tabular}

Table 4 (continued) 
Table 4 (continued)

\begin{tabular}{|c|c|c|c|c|}
\hline Characteristics & $\begin{array}{l}\text { Class 1: passive } \\
(\mathrm{n}=226), \mathrm{n}(\%)\end{array}$ & $\begin{array}{l}\text { Class 2: unmotivated } \\
\qquad(\mathrm{n}=124), \mathrm{n}(\%)\end{array}$ & $\begin{array}{l}\text { Class 3: proactive } \\
\qquad(\mathrm{n}=721), \mathrm{n}(\%)\end{array}$ & $P$ value \\
\hline Are you a smoker? & & & & 0.258 \\
\hline Never & $134(61.19)$ & $83(68.60)$ & $452(66.67)$ & \\
\hline Ever smoker & $85(38.81)$ & $38(31.40)$ & $226(33.33)$ & \\
\hline $\begin{array}{l}\text { Were you ever been exposed to passive smoke during } \\
\text { you childhood? }\end{array}$ & $139(62.61)$ & $79(65.83)$ & $443(65.05)$ & 0.770 \\
\hline \multicolumn{5}{|l|}{ Discussed topics } \\
\hline Does any member of your family smoke? & $108(49.54)$ & $51(47.66)$ & $429(68.53)$ & $<0.001$ \\
\hline Does anyone smoke in the presence of your child? & $191(86.04)$ & $103(88.79)$ & $598(90.88)$ & 0.119 \\
\hline Does anyone smoke inside your car? & $156(69.96)$ & $86(78.18)$ & $502(78.93)$ & 0.022 \\
\hline $\begin{array}{l}\text { Did you make efforts to prevent your child's passive } \\
\text { smoking? }\end{array}$ & $145(65.91)$ & $89(82.41)$ & $488(78.08)$ & $<0.001$ \\
\hline $\begin{array}{l}\text { Is the parent aware of the consequences of passive } \\
\text { smoking on the health of the child? }\end{array}$ & $169(75.11)$ & $93(81.58)$ & $530(80.67)$ & 0.172 \\
\hline $\begin{array}{l}\text { Do you provide information on the effects on children's } \\
\text { health caused by exposure to passive smoking? }\end{array}$ & $184(82.88)$ & 101 (82.79) & 617 (89.03) & 0.021 \\
\hline $\begin{array}{l}\text { Could you indicate your difficulty in dealing with the } \\
\text { argument of overweight and/or obesity in children } \\
\text { during the medical examination? }\end{array}$ & $153(71.50)$ & 81 (72.97) & $448(70.66)$ & 0.876 \\
\hline $\begin{array}{l}\text { Could you indicate what is your degree of difficulty in } \\
\text { dealing with the topic of parental negligence towards } \\
\text { children during the medical examination? }\end{array}$ & $56(26.42)$ & $42(38.18)$ & 177 (28.69) & 0.076 \\
\hline $\begin{array}{l}\text { Could you indicate what your difficulty level is in } \\
\text { addressing the subject of child abuse during the } \\
\text { medical examination? }\end{array}$ & $23(11.00)$ & $23(20.72)$ & 79 (12.93) & 0.044 \\
\hline $\begin{array}{l}\text { Could you indicate what is your difficulty level in } \\
\text { addressing the topic of exposure of the child to } \\
\text { passive smoking during the medical examination? }\end{array}$ & $178(83.57)$ & $91(79.82)$ & $534(85.03)$ & 0.366 \\
\hline $\begin{array}{l}\text { Could you indicate what your difficulty level is in } \\
\text { addressing the subject of parent's dependencies } \\
\text { during the medical examination? }\end{array}$ & 68 (32.69) & $45(42.45)$ & 267 (43.84) & 0.018 \\
\hline $\begin{array}{l}\text { Do you advise smokers in the family to stop smoking } \\
\text { in the presence of the child? }\end{array}$ & 197 (97.04) & $103(97.17)$ & $600(97.72)$ & 0.842 \\
\hline \multicolumn{5}{|c|}{ From your point of view, who is in charge of discussing exposure to passive smoking in children? } \\
\hline Paediatrician & $215(95.13)$ & $111(89.52)$ & $659(91.40)$ & 0.111 \\
\hline Pulmonologist & $27(11.95)$ & $23(18.55)$ & $108(14.98)$ & 0.239 \\
\hline General medical practitioner & $45(19.91)$ & $30(24.19)$ & $161(22.33)$ & 0.617 \\
\hline $\begin{array}{l}\text { Have you ever received post-graduate training on } \\
\text { exposure to passive smoking in children? }\end{array}$ & $106(49.07)$ & $51(42.15)$ & $294(43.43)$ & 0.299 \\
\hline $\begin{array}{l}\text { Would you be interested in receiving training on } \\
\text { exposure to passive smoking in children? }\end{array}$ & $176(79.28)$ & $95(77.87)$ & $536(79.41)$ & 0.928 \\
\hline
\end{tabular}

LCA, latent class analysis. 


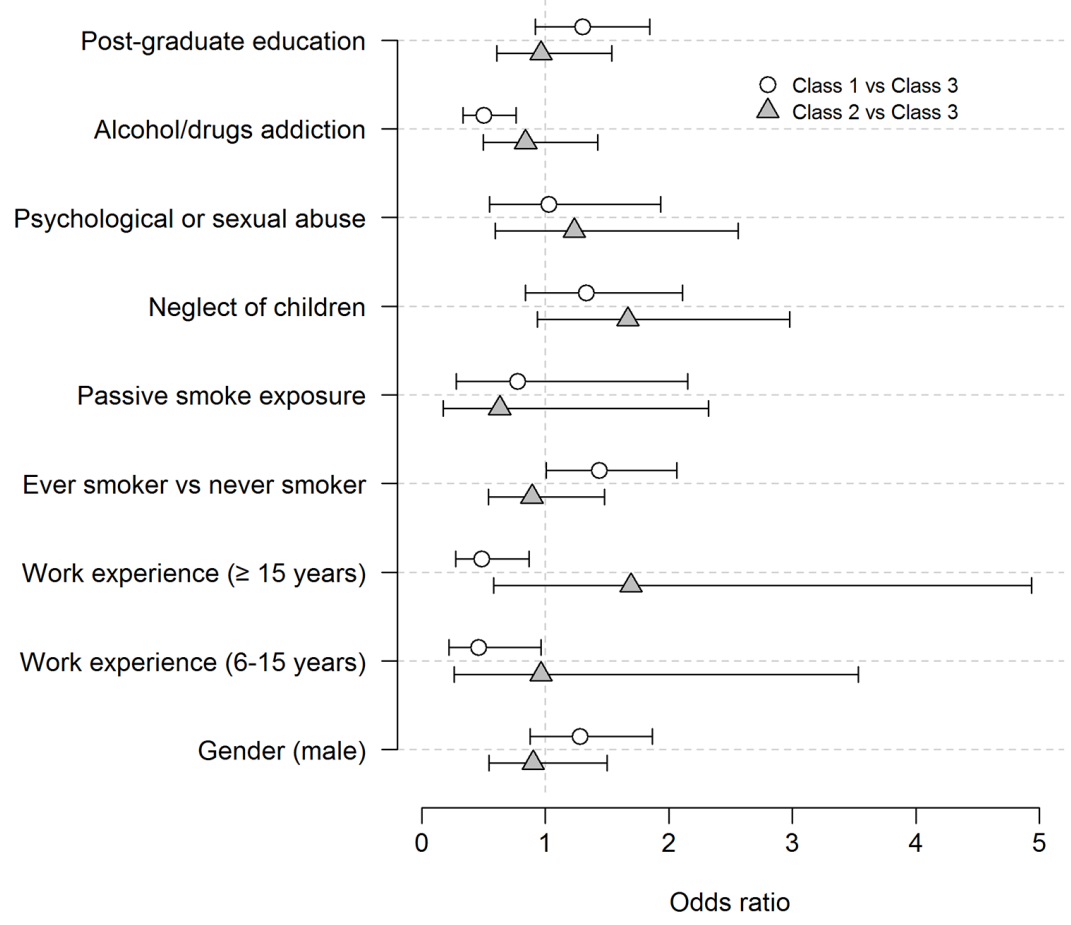

Figure 3 OR and 95\% confidence intervals from the multinomial regression for inclusion into a class. Circles indicate ORs from comparison between Class 1 vs. Class 3; triangles indicate OR from comparison between Class 2 vs. Class 3. OR, odds ratio.

Significant differences among classes were observed with regard to the topics discussed with parents/ caregivers during the medical visit. In particular, "passive" paediatricians less frequently discussed issues such as smoking in the car, preventing children from passive smoke and parents' addiction to alcohol/drugs; "unmotivated" paediatricians had more frequently $\geq 15$ years of experience and less often than the other two classes discussed the issue of having smoking relatives, although they more frequently asked about psychological or sexual abuse; "proactive" paediatricians more frequently discussed smoking habits in the family, provided information about the effects on children's health of passive smoke exposure and approached parents' addiction to alcohol/drugs.

In line with previous studies, the most frequently reported barriers in the current study were related to privacy and lack of time $(13,19,20)$. Paediatricians more prone to act as smoking cessation promoters were the most incentivized ones; in particular, the sensory perception of children who smell of tobacco, as well as the evidence of active smoking in parents were the incentives that most often stimulated paediatricians to assess PSEC. Asthma diagnosis in children exposed to passive smoke represented another factor contributing to increase the paediatricians' propensity to talk about the topic. Thus, the acknowledgement of diseases likely influenced by passive smoke exposure leads to more intensive behavioral counseling.

The current study attempted to investigate risk factors for latent inclusion into a class using a multinomial logistic regression model. Being an ever smoker was associated with an increased probability of inclusion into the passive class. Conversely, having over 5 years of work experience and discussing parents' addiction to alcohol/drugs was associated with a decreased probability of inclusion into such class. Of note, a previous study of Italian general practitioners demonstrated that those practicing for $\geq 12$ years showed greater knowledge of the impact of PSEC, whereas having ever smoked was associated with a lower level of knowledge (21). This suggests that personal factors may influence physician's attitudes toward smoking cessation. The physician's work experience could provide greater confidence in addressing smoking cessation, and in contrast, being ever smoker seemed to limit paediatricians' emphasis on counseling and referring caregivers. Indeed, paediatricians who are not used to approach smoking cessation are also less prone to discuss other issues of 
concern, such as parents' addiction to alcohol/drugs (22).

Moreover, evidence suggests that risk behaviors are clustered: those who engage in one risk behavior are more likely to engage in others (23). Therefore, paediatricians should incorporate substance-abuse prevention in their practice and provide or facilitate assessment, intervention and treatment when necessary. No significant associations were found when comparing unmotivated and proactive.

Overall, these findings suggest that incentives are the factor which best discriminates among the three classes. Therefore, the attitude of paediatricians in promoting smoking cessation may be ascribed to their knowledge of the detrimental effect of SHS on children's health. Unfortunately, the tobacco-related content in medical school and continuing education curricula remains scanty. To bring meaningful change, institutions should emphasize the role of the educational system in prioritizing tobacco information and promoting paediatrician's competency in tobacco control and treatment (24).

There are some limitations to our study. First, the crosssectional design is not suitable to verify direction of causality about the observed associations. A second limitation is the potential for self-reported bias, which is prone to recall bias through a questionnaire. Although the intrinsic inaccuracy of self-reports should be considered, anonymized data from questionnaires could have reduced respondent bias.

Nonetheless, this study benefited from an advanced statistical analysis. The use of LCA can be considered a novel approach in this research field. In addition, the latent clustering numbers were not pre-set before analysis, so the decision to adopt a particular model is less subjective (25).

In conclusion, we provided evidence to show that some barriers and incentives may influence paediatricians' skills while screening and counseling SHS in children. These preliminary results are promising for developing MAPed ad hoc training courses aimed at increasing knowledge and skills of PCPs in delivering adequate advice to smokers. In this context, MAPed training courses will include tailored measures according to the different paediatricians' attitude towards smoking cessation promotion. Therefore, customized intervention strategies could be developed, such as learning and empowerment courses for "passive" and "unmotivated" paediatricians, respectively. At last, "proactive" paediatricians may play an assistant role flanking the expert panel, since they are the most skilled and motivated children doctors in this field. In addition, it is important that medical students acquire knowledge and skills which will allow them to actively engage in advising smokers to quit in their future clinical practice. Hence, they should receive $a d$-boc training courses, and a tobacco module should be included in the curriculum of every university medical school.

\section{Acknowledgments}

We are grateful to all the paediatricians participated to the survey and the Italian Paediatric Respiratory Society (IPRS) (SIMRI) who made the study possible.

Funding: None.

\section{Footnote}

Provenance and Peer Review: This article was commissioned by the GARD Section Directors (Yousser Mohammad, Alvaro A. Cruz) for the "GARD Section" published in Fournal of Thoracic Disease. The article was sent for external peer review organized by the Guest Editor and the editorial office.

Reporting Checklist: The authors have completed the STROBE reporting checklist. Available at http://dx. doi. org/10. 21037/jtd-gard-20-003

Data Sharing Statement: Available at http://dx. doi. org/10. 21037/jtd-gard-20-003

Conflicts of Interest: All authors have completed the ICMJE uniform disclosure form (http://dx. doi. org/10.21037/jtdgard-20-003). The authors have no conflicts of interest to declare.

Ethical Statement: The authors are accountable for all aspects of the work in ensuring that questions related to the accuracy or integrity of any part of the work are appropriately investigated and resolved. Since the authors have not conducted human experiments, the authors have not reported Statement on Declaration of Helsinki (as revised in 2013). All participating pediatricians were fully informed about the aim of this survey at their entry to the website with a popup notice designed to confirm this. A separate informed consent is therefore waived, as decided by GARD Executive Committee.

Open Access Statement: This is an Open Access article distributed in accordance with the Creative Commons Attribution-NonCommercial-NoDerivs 4.0 International 
License (CC BY-NC-ND 4.0), which permits the noncommercial replication and distribution of the article with the strict proviso that no changes or edits are made and the original work is properly cited (including links to both the formal publication through the relevant DOI and the license). See: https://creativecommons.org/licenses/by-nc-nd/4.0/.

\section{References}

1. Best D, Committee on Environmental Health, Committee on Native American Child Health, et al. From the American Academy of Pediatrics: technical report-secondhand and prenatal tobacco smoke exposure. Pediatrics 2009;124:e1017-44.

2. Drago G, Perrino C, Canepari S, et al. Relationship between domestic smoking and metals and rare earth elements concentration in indoor PM2. 5. Environ Res 2018;165:71-80.

3. Ferrante G, Antona R, Malizia V, et al. Smoke exposure as a risk factor for asthma in childhood: a review of current evidence. Allergy Asthma Proc 2014;35:454-61.

4. World Health Organization. WHO report on the global tobacco epidemic, 2019: offer help to quit tobacco use: executive summary. In: WHO report on the global tobacco epidemic, 2019: offer help to quit tobacco use: executive summary, 2019.

5. Beaty T, Dornelles AC, Sahuque T, et al. Evaluation of pediatricians' adherence to tobacco prevention, control, and treatment guidelines before and after an educational outreach program. Ochsner J 2013;13:375-9.

6. Winickoff JP, Buckley VJ, Palfrey JS, et al. Intervention with parental smokers in an outpatient pediatric clinic using counseling and nicotine replacement. Pediatrics 2003;112:1127-33.

7. Nabi-Burza E, Winickoff JP, Finch S, et al. Triple tobacco screen: opportunity to help families become smokefree. Am J Prev Med 2013;45:728-31.

8. Pérez-Stable EJ, Juarez-Reyes M, Kaplan CP, et al. Counseling smoking parents of young children: comparison of pediatricians and family physicians. Arch Pediatr Adolesc Med 2001;155:25-31.

9. Victor JC, Brewster JM, Ferrence R, et al. Tobacco-related medical education and physician interventions with parents who smoke: Survey of Canadian family physicians and pediatricians. Can Fam Physician 2010;56:157-63.

10. Hymowitz N. Pediatric residency training on tobacco: review and critique of the literature. J Natl Med Assoc 2006;98:1489.
11. Ng N, Prabandari YS, Padmawati RS, et al. Physician assessment of patient smoking in Indonesia: a public health priority. Tob Control 2007;16:190-6.

12. Hall K, Kisely S, Gastanaduy M, et al. Pediatricians' Confidence and Behaviors in Smoking Cessation Promotion and Knowledge of the Smoking Cessation Trust. Ochsner J 2016;16:130-5.

13. Hutchinson SG, Kuijlaars JS, Mesters I, et al. Addressing passive smoking in children. PLoS One 2014;9:e93220.

14. Collins LM, Lanza ST. Latent class and latent transition analysis: With applications in the social, behavioral, and health sciences. John Wiley \& Sons; 2010; Vol. 718.

15. Nosetti L, Paglietti MG, Brunetti L, et al. Application of latent class analysis in assessing the awareness, attitude, practice and satisfaction of paediatricians on sleep disorder management in children in Italy. PLoS One 2020;15:e228377.

16. Ferrante G, Fondacaro C, Cilluffo G, et al. Identification of bronchiolitis profiles in Italian children through the application of latent class analysis. Ital J Pediatr 2020;46:147.

17. McLachlan GJ, Lee SX, Rathnayake SI. Finite mixture models. Annu Rev Appl Stat 2019;6:355-78.

18. Anderson D, Burnham K, White G. Comparison of Akaike information criterion and consistent Akaike information criterion for model selection and statistical inference from capture-recapture studies. J Appl Statist 1998;25:263-82.

19. Meijer E, van der Kleij R, Segaar D, et al. Determinants of providing smoking cessation care in five groups of healthcare professionals: A cross-sectional comparison. Patient Educ Couns 2019;102:1140-9.

20. Garg A, Serwint JR, Higman S, et al. Self-efficacy for smoking cessation counseling parents in primary care: an office-based intervention for pediatricians and family physicians. Clin Pediat 2007;46:252-7.

21. Unim B, Del Prete G, Gualano MR, et al. Are age and gender associated to tobacco use and knowledge among general practitioners? Results of a survey in Italy. Ann Ist Super Sanita 2013;49:266-71.

22. Kulig JW, American Academy of Pediatrics Committee on Substance Abuse. Tobacco, alcohol, and other drugs: the role of the pediatrician in prevention, identification, and management of substance abuse. Pediatrics 2005;115:816-21.

23. DuRant RH, Smith JA, Kreiter SR, et al. The relationship between early age of onset of initial substance use and engaging in multiple health risk behaviors among young adolescents. Arch Pediatr Adolesc Med 1999;153:286-91. 
24. Powers CA, Zapka JG, Bognar B, et al. Evaluation of current tobacco curriculum at 12 US medical schools. J Cancer Educ 2004;19:212-9.

25. Schreiber JB, Pekarik AJ. Using Latent Class Analysis

Cite this article as: Cilluffo G, Ferrante G, Cutrera R, Piacentini G, Bignamini E, Landi M, Martucci P, Morcaldi L, Midulla F, Viegi G, La Grutta S. Barriers and incentives for Italian paediatricians to become smoking cessation promoters: a GARD-Italy Demonstration Project. J Thorac Dis 2020;12(11):6868-6879. doi: 10.21037/jtd-gard-20-003 versus K-means or Hierarchical Clustering to understand museum visitors. Curator The Museum Journal 2014;57:45-59. 